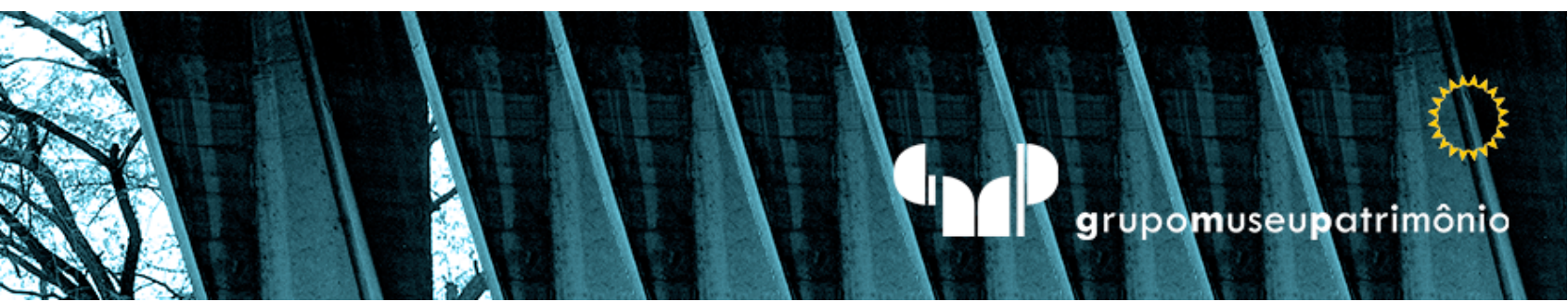

\title{
Ecossemântica do mundo arte
}

\author{
Ecosemantica del mundo del arte
}

Ecosemantics of the art world

\begin{abstract}
Ana Sofia Ribeiro
Estudante de Mestrado da Faculdade de Belas Artes da Universidade do Porto.up201506702@fba.up.pt

Teresa Almeida

I2ads, Faculdade de Belas Artes da Universidade do Porto; VICARTEVidro e cerâmica para as Artes. talmeida@fba.up.pt
\end{abstract}




\section{Resumo}

O presente artigo pretende explorar a relação convergente entre a ecologia e a arte contemporânea, através do questionamento da indefinição semântica que diz respeito à insurgência da ética ecológica na produção de arte a partir de 1960, nomeadamente em movimentos como a Land art e Environmental art, com o intuito de aferir um sentido mais pragmático da Ecological art no atual mundo da arte.

Palavras-chave: Ecocêntrico. Land art. Ecological art. Environmental art. Ecologia.

\section{Abstract}

This article intends to explore the convergent relationship between ecology and contemporary art, by questioning the semantic uncertainty that concerns the insurgency of ecological ethics in art production from the 1960s, namely in movements such as Land art and Environmental art, in order to assess a more pragmatic definition of Ecological art in the current art world.

Keywords: Ecocentric. Land art. Ecological art. Environmental art. Ecology.

\section{Resumen}

Este artículo pretende explorar la relación convergente entre la ecología y el arte contemporáneo, cuestionando la incertidumbre semántica que concierne a la insurgencia de la ética ecológica en la producción artística de la década de 1960, concretamente en movimientos como la Land art y Environmental art, con el fin de determinar una definición más pragmática. del Ecological art en el actual mundo del arte.

Palabras clave: Ecocéntrico. Land art. Ecological art. Environmental art. Ecología. 


\section{INTRODUÇÃO}

Atualmente, tem-se assistido ao desenvolvimento acrescido do aquecimento global, da destruição da camada do ozônio, da devastação da biodiversidade e da extinção em massa de espécies. Estes fatores, sendo impossíveis de ignorar, envolveram a tentativa de reformulação contínua de valores éticos, sociais, políticos e econômicos, em prol de garantir o futuro das próximas gerações. Assim com a insurgência das preocupações éticas ambientais, prósperas de autores como Henry David Thoreau, Félix Guattari e Arne Næss, e devido a efeitos combinados da crise climática, do ecocídio e de um medo fundamentado do fim, tornou-se inevitável a convergência do contexto ético, político e social com a arte.

O artista da década de 60 do século XX começou a trabalhar sobre a crítica institucional como um meio de denúncia do mundo da arte. Este tinha como objetivo provocar a transformação e demonstrar a sua insatisfação para com a sua realidade. Frequentemente, a esta é associada uma estética naturalista proveniente do contexto sociopolítico da época em que se gera. Em particular, a guerra do Vietnam, a massificação, o desenvolvimento tecnológico, as questões ambientais e o capitalismo provocaram em muitos artistas um anseio por mudança, induzindo-os a uma revolução da sua própria forma de expressão através da contradição dos meios mais tradicionais de produção de arte. Neste contexto, tanto Land art, como a Arte 
povera ou até mesmo a Pop art, podem ser associadas a este parecer de revolta contra o sistema capitalista ao qual o mundo da arte se enquadra e o natural se desvanece. Querendo isto dizer, que quando observadas as esculturas de Joseph Penone, a instalação Running Fence de Christo e Jeanne-Claude ou as flores de Andy Warhol de 1964, poder-se-á ver nelas uma ligação e valorização das éticas verdes por via de correlação à Natureza, mas que suscitam algumas dúvidas quanto à sua inserção na Ecological art, desenvolvida durante esta época. Dada uma certa incoerência entre o discurso e a prática artística, poder-se-á, então, questionar se é a intenção da arte provocar uma mudança na realidade e mentalidade do seu espectador ou apenas aproximar-se do próximo avant-garde. Por essa razão, explorar a Environmental art, Ecological art ou a Sustainable art implica perceber o quão intercambiável estes termos têm sido no mundo da arte e procurar estabelecer parâmetros concretos da aplicação do prefixo "eco" à arte contemporânea.

Este artigo considera, então, a reformulação de toda ética e moral associada à Natureza na arte, tentando entender os fatores que estabelecem uma obra de arte como sendo considerada ecológica, procurar distinguir o que é ou não denominado e formular normas precisas que facilitem entender este conceito. No entanto, ainda que exorcizadas certas noções, não ocorrerá a desvalorização das suas contribuições para o estabelecimento da ecologia na arte como um movimento em si mesmo. Posto isto, através da análise da perspetiva da Ecoart Network, de Suzi Gablik e de Linda Weintraub, tendo como fundamento a ética ecológica e dispondo como caso de estudo a Land art, tentar-se-á estipular os parâmetros de fundação anteriores e perceber as transferências semânticas contemporâneas do prefixo "eco" na arte.

\section{PERMUtABILIDADE DO TERMO “ECO" NO MUNDO DA ARTE}

Reafirmando a Natureza como centro do discurso da produção artística, evidenciouse a pertinência de saber com que intenção, para quem e de que posição se fala. É, então, a partir de uma distanciação da origem da questão, que se discute sobre a permanência e evolução do termo "eco" na estética e na teoria conceptual do objeto artístico, que aparenta continuar a provocar, até a atualidade, alguma incerteza no mundo da arte. 
Assim sendo, introduz-se a palavra "ecologia", cunhada pela fundadora do ecofeminismo Ellen Swallow Richards, que tendo como base a palavra grega "lar", da qual Ernst Haeckel faz a transição para "lar na Natureza", vai fundamentar os princípios de muita da arte dita ecológica. É descrito pela crítica de arte, ativista e curadora Lucy Lippard que muita da ecologia na arte começa por demonstrar esse desejo referente de retorno ao "lar" dada a inquietação social proeminente na época em que se funda e que, à vista disso, exige um movimento ativo, preocupado, de baixo perfil e com atitudes mais sensíveis em relação aos ecossistemas, querendo isto dizer, uma arte praticante de estratégias mais efêmeras, menos intrusivas e comedidas, que questionam, coincidentemente, a verosimilhança de outros movimentos com as mesmas ditas preocupações. (LIPPARD, 1995)

Segundo Sacha Kagan, a origem do termo Ecological art aparece por volta da década de 90, como forma de qualificar as práticas artísticas que surgiram nos finais dos anos 60 em diante. A sua normativa implica associar o termo de forma abrangente o suficiente para incluir movimentos tão distintos como a Land art, Eco-art, Art in nature, Arte povera e a Sustainable art. (KAGAN, 2014) Porém, como se podem estabelecer ligações entre uma estética que conceitualmente busca a proteção ambiental, com uma expressão artística da qual a sua matriz permite a agressiva exploração do meio ambiente ou, ainda paradoxalmente, a contribuição para a crise climática. Talvez possamos analisá-la como um oxímoro ou, até mesmo, através da perspetiva de Ellen Swallow Richards, anteriormente referida, na qual a arte explora apenas uma relação de causalidade de convergência com o natural em proveito de objetivos distintos. Contudo, será melhor a sua análise.

Nomeadamente, a Land ou Earth art, cunhada por Robert Smithson, sendo majoritariamente escultórica ou performativa, desenvolve-se embebida num contexto social pós-guerra e numa nostalgia do pré-industrial, ilustrado pela publicação de Silent Spring de Rachel Carson, em 1962, e pela celebração do primeiro Dia da Terra, em abril de 1970, que se considera que tenham projetado o pensamento ecológico. Os earthmovers ou earthworkers exibidos pela primeira vez em 1968, na Dwan Gallery, em Nova York, procuram em suas práticas salientar e restabelecer a relação espiritual e emocional que fora perdida na sociedade do hiperconsumo entre o Homem e a 
Natureza. Objetivamente, a Land art proporcionou, ainda, o crescimento de um subgrupo chamado de Environmental art, sincrônico e espelhado a partir do ecoactivist. Este pretendia ter uma estética de ação em oposição à poetização da Natureza da Land art, dado que presenteavam a mesma como pouco ambiciosa e como não tendo resolvido o dilema em questão. (KASTNER \& WALLIS, 1998) Será, então, categórico pensar a Environmental art como uma contracultura que contesta o seu próprio criador e que marca o início de um julgamento inerente à assimilação das diferentes expressões artísticas à Ecological art.

O crítico de arte Jeffrey Kastner descreve a Land art como um termo que é um "hipônimo imperfeito para uma marca escorregadia e amplamente interconectada de parentesco conceitual". (KASTNER \& WALLIS, 1998, p. 12) (tradução livre) O autor desenvolve sua premissa reafirmando que, mesmo procurando uma reconexão ativista conceitual biocêntrica e um ativismo prático, já tardio, de uma biosfera não industrializada, sua fundação acaba por se relacionar mais com manifestações modernistas, minimalistas ou conceituais, das quais as inquietações principais revolvem em torno do tempo e como as forças da natureza tem impacto nos objetos e gestos, resultando alternadamente numa abordagem agressiva ou provedora dos ecossistemas. (Ibidem) A Land art não se afirma, então, essencialmente como consciente e pivô do discurso ecológico, proveniente dessa mesma época, podendo apenas ver nela a capacidade de o ser. Esta subjetiva bipolaridade refuta o argumento de que a Land art, em si mesma, seja toda ela associada à Ecological art.

De forma similar, até mesmo a Environmental art, segundo o artista Kenneth Friedman, vem a ser utilizada, posteriormente, como um termo que resume a imagética inerente à Land art ou às formas de arte que envolvem uma investigação ecológica, sendo estes ambivalentes da cultura e da Natureza. (Kastner \& Wallis, 1998) A esta ambiguidade semântica, ao não distinguir os movimentos entre si, sucede uma alienação do movimento ecológico na arte, o que o torna alvo de crítica. Como se pode, então, comparar e encaixar a magnitude e intemporalidade, influenciada por uma noção apocalíptica proveniente da guerra do Vietnam e do Double Negative de Michael Heizer às noções biocêntricas e quase misantropas de Thoreau, que conduziram as caminhadas solitárias de Richard Long. 
Lucy Lippard subscreve desta forma:

\begin{abstract}
"Embora tenha havido muitas críticas ao aspeto anti-ecológico dos earthworks de grande escala que perfuram e alteram a terra de maneira para-industrial, as grandes obras não são inerentemente mais dominadoras do que as pequenas. É a atitude em relação à Terra, a sensibilidade do artista ao lugar que determina o efeito do imaginário." (LIPPARD, 1995, p. 52) (tradução livre)
\end{abstract}

Neste sentido, uma atitude prática e teórica para com a obra de arte torna-se fundamental para a inserção livre de falácias discursivas, não bastando haver um interesse pelo biomorfismo ou pelo retorno do extra-human e do pre-worldly, mas antes uma intenção coerente e compreendida, em todos os seus aspetos.

No entanto, poder-se-á pôr, ainda, em causa o quão consciente deve estar assente essa atitude. Pondo sob observação a Arte povera e o seu interesse alquimista pelos aspetos mais morfológicos e estruturalistas da Natureza, poderá ver-se na sua constituição o simultâneo apelo à sustentabilidade sem que essa seja sua intenção. Em outras palavras, ainda que Germano Celant descreva o movimento como aquele que não expressa uma sentença ou que não busca um julgamento moral ou social, apenas a sua intenção de romper com os processos industriais através do uso de materiais considerados pobres e insólitos ao mundo da arte, revela uma crítica não intencionada da sociedade de consumo (CELANT, 1969), gerando-se, assim, uma dissonância entre as suas intenções e as ações artísticas. Consequentemente, aquilo que foi gerado a partir de uma exploração da autorrepresentação e do autodescobrimento que ignora o seu contexto sociopolítico acaba por sofrer uma metamorfose conceitual concebida por interpretações exteriores à obra, levantando a questão será a Arte povera ecológica?

Notamos, então, o quão intercambiável e aplicável é a conotação ecológica na arte, seja por se ter um discurso conceitual que apele, uma intenção artística in/consciente crítica, uma produção prática exemplificativa, uma inserção espacial/ambiental positiva ou uma teoria ideológica ecológica. Por essa razão, serão, em seguida, exploradas três abordagens mais pragmáticas, cujo objetivo é tentar, de forma coesa, estruturar e regulamentar essa terminologia, e restringir a 
associação de determinados movimentos artísticos e respectivas obras de arte à tão incompreendida Ecological art.

\section{PRAGMATISMO TERMINOLÓGICO DA ECOLOGICAL ART NA ATUALIDADE}

A autodefinição de 2011 desenvolvida pela Ecoart Network (uma congregação de mais de uma centena de artistas e críticos, criada em 1998 com o objetivo de partilhar e discutir assuntos relacionados com arte e ecologia) descreve a Ecological art como um movimento que adota uma ética ecológica em ambas as áreas de forma e matéria. Segundo Hull, Oakes, \& Steinman (1998), os artistas que se enquadrem nela seguem os seguintes princípios:

(1) concedem atenção aos aspetos físicos, biológicos, culturais, políticos e históricos dos sistemas ecológicos;

(2) criam obras a partir de materiais naturais ou que interagem com as forças da natureza;

(3) recuperam, corrigem ou restauram locais já devastados;

(4) informam o espectador sobre as dinâmicas e problemas ecológicos,

(5) repensam novas formas criativas de coexistência, sustentabilidade e de recuperação da Natureza.

Sob outra perspetiva, a historiadora, artista e crítica de arte, Suzi Gablik, descreve o movimento ecológico a partir de uma relação simbiótica e de conectividade com todos os seres vivos, em oposição a uma visão individualista do Homem no mundo. O movimento é também caracterizado por uma prática que promove a reformulação, mais sustentável, da forma como vivemos, mas sem que esta destrua o sistema social moderno e visando uma transformação em vez de uma representação. A obra de arte ecológica, a seu ver, nunca é inútil no sentido da arte pela arte, mas também não é funcional em termos de cumprir uma função definida, tendo, então, de ter um discurso útil. Já o artista ecológico é retratado como o que exerce a sua responsabilidade ética em torno de comunidades humanas e não humanas. (Kagan, 2014) 
Mais explicitamente, a escritora e curadora Linda Weintraub, em seu livro To Life!: Eco Art in Pursuit of a Sustainable Planet, evidencia a arte ecológica como uma missão e não como um estilo, da qual o artista tem de justificar a adoção do prefixo "eco". Desta maneira, define quatro atributos que influenciam a prática artística e que redefinem este movimento, dos quais se apresentam como:

Tópicos: o primeiro atributo representa as oportunidades retiradas da rigorosidade comportamental ecologista (organismos não humanos, o ambiente não vivo e as ações humanas condicionam o tempo, o espaço, o comportamento, a física e química na Terra) e da subjetividade comportamental ambientalista (a intuição, opinião e interpretação justificam o discurso artístico) que resultam no uso de diferentes materiais, formas de expressão e escalas de interação (global/local).

Interconexão: o segundo atributo refere-se à amplificação da relação com a Terra através da aceitação das condições que ela Ihe impõe. Coloca, assim, o Homem como parte da Natureza, reafirmando o axioma ecológico por meio de sistema, rede, sinergia, coevolução, comunidade, comensalismo, mutualismo, simbiose, competição, mimetismo, feedback e sucessão, que transformam a obra de arte em concordância com o contexto em que se insere.

Dinamismo: o terceiro atributo reconhece o próprio tempo como um interveniente na criação artística. Considera as permutações perpétuas do ciclo da vida como um fator necessário da obra, estando ao critério do artista relativizar/prever o ritmo da sua efemeridade ou coreografar o seu próprio fim, enfatizando a ação e a transformação sobre o objeto e a estética.

Ecocentrismo: opostamente ao antropocentrismo, recusa a ideia de que o Homem é mais importante do que qualquer outra espécie, colocando-o, antes, no mesmo nível com o objetivo de mover mais pessoas na direção ecológica e ambientalista. Porém, é também capaz de guiar o artista quanto ao tema, recursos gastos e desperdícios feitos a cada momento do processo criativo. (Weintraub, 2012)

Se, então, utilizarmos a Land art (Fig.1, 2 e 3) como caso de análise, notamos que esta não respeita as características mais determinantes do movimento descrito pelas 
diferentes perspetivas. Fundamentalmente, a Land art não reformula o seu pensamento sob uma visão ecocêntrica, não tem como intenção principal denunciar ou informar o espectador dos problemas ecológicos, não repensa majoritariamente os seus materiais e processo de produção conforme uma teoria sustentável ou preocupada com o espaço em redor e não transfere comportamentos ambientalistas para a ação artística, interferindo muitas das vezes no próprio ecossistema.
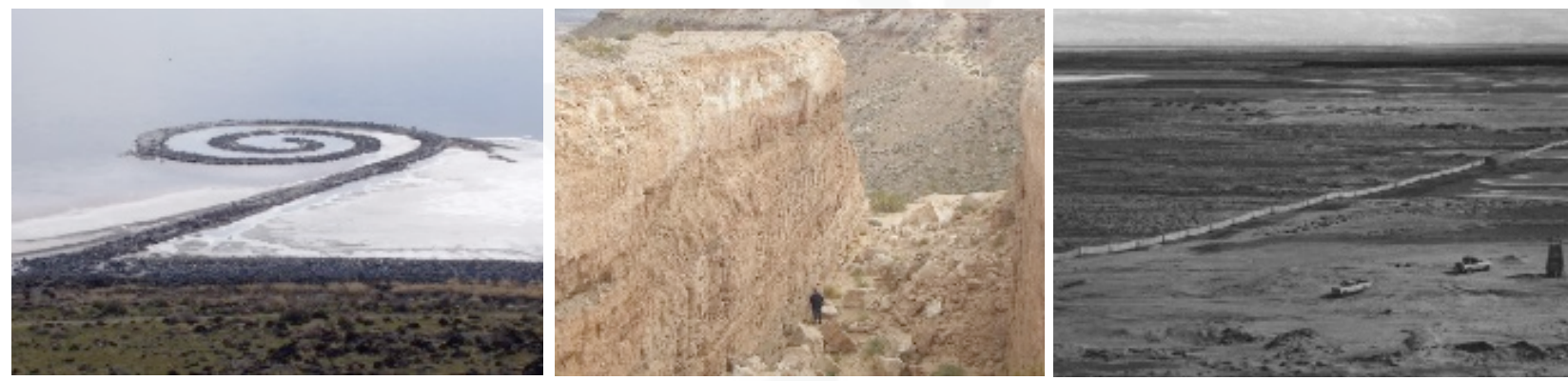

Fig.1 (à esquerda) Spiral Jetty, 1970. Fonte: Wikimedia Commons. Fig.2 (centro) Double Negative, 1969-70. Fonte: Wikimedia Commons. Fig.3 (à direita) Running Fence, 1972-76. Fonte: Public domain

Exemplo disso seria a Spiral Jetty (Fig. 1) de Robert Smithson, que revela o interesse de seu criador pela alteração do território e paisagem, na qual a inserção humana é vista como uma consequência natural e cuja intervenção, ainda que aplicada a um espaço inóspito, não repensa formas de recuperação ou de reabilitação. Reflete, antes, sobre um novo paradigma de exposição, que, segundo Brian Wallis, explora a arte fora da instituição (site and non site) e a alteração ecossistêmica, em oposição ao mercado da arte (Kastner \& Wallis, 1998); também a Double Negative (Fig. 2) de Michael Heizer demonstra como a conjugação artística com a paisagem acaba por destruir em vez de melhorar o ecossistema envolvente, homologando sua consciência para com a exploração artística e não para com a Natureza; ou ainda a Running Fence (Fig.3) de Christo e Jeanne-Claude, por toda a controvérsia envolvida na sua permanência física, que se demonstrou um transtorno ambiental e que fez circular as estruturas econômicas, sociais e políticas que governam a paisagem, pela sua megalomania, imensidade e negligência processual ecológica. (Beardsley, 1998)

Em retrospetiva, estas definições refletem em si o mesmo objetivo: estabelecer concretamente o que é a Ecological art e que obras de arte se podem inserir nela. 
Todavia, ainda que equivalentes, será percetível alguma distinção entre a definição da Ecoart Network/Linda Weintraub e a de Suzi Gablik, dado seu posicionamento antropocêntrico, que acaba por gerar resultados hesitantes, inseguros, com abertura para discussão e que questionam o papel da estética e do artista em diálogo com a crise climática, um dos inúmeros temas ambientais/ecológicos cuja demanda por posicionamento político e crítico é urgente. Deste modo, propõe-se revisitar as éticas ecológicas, que parecem, paralelamente, descrever esse paradigma artístico.

\section{ECOCENTRISMO COMO MEDIADOR DA ECOLOGICAL ART E DO MUNDO DA ARTE}

O ecocentrismo, ao estabelecer a intenção do utilitarismo em termos de consequências das ações humanas em favor do bem comum são valorizadas acima dos direitos individuais e ao ser complementado pela inclusão de todas as formas de vida (humanas, não humanas e ecossistemas), estratifica a prática artística sobre valores éticos ecológicos. Além disto, o que torna o ecocentrismo fundamental para entender as dissemelhanças entre as diferentes definições acerca da relação ArteNatureza, é o conjunto de suas ramificações ou escala cêntrica ${ }^{1}$. Ou seja, este apresenta três filosofias distintas referentes à forma como se posiciona o valor no Homem comparativamente à Natureza, sendo:

(1) a light green ou shallow ethic (uma ética levemente verde ou rasa): aquela que foca a sua atenção na Natureza apenas quando esta implica a sobrevivência humana, não alterando a sua perspetiva antropocêntrica e sobrevalorizando a sabedoria humana para regê-la;

(2) a mid-green ou intermediate ethic (uma ética medianamente verde ou intermediária): que nega o valor intrinsecamente único do Homem, colocando-o antes como sendo superior a outras formas de vida e que, mesmo considerando as

\footnotetext{
1 “Assim as éticas ambientais, nas suas variadas formas, shallow e deep, utilitárias ou deontológicas, são todas e cada uma ética; algumas delas têm como objetivo fornecer tanto uma teoria da moralidade, como uma moralidade defendida, características da própria prática e, portanto, não apenas vincular a prática (pela qual as pessoas vivem) e a teoria, mas também eliminar possíveis ambiguidades." (Bennett \& Sylvan, 1994, p. 3) (tradução livre)
} 
questões ambientais como uma preocupação moral, em momentos de confronto de valores acaba por ter prioridade sobre elas;

Ecocentrismo:
Dark Green Ethics
Linda Weintraub
Ecoart network
Mid-green:
Suzi Gablik
Crop Art
Bio Art

Light green:
Land art
Arte povera
Art in nature

Fntropocentrismo:
Pop art
Futurismo
Neoclassicismo
Foboco uma escala Ana Ribeiro
ecocolrica, 2021
Fonte:

(3) e a dark green ou deep ethic (uma ética verde pesada ou profunda): que sendo puramente ecocêntrica, posiciona as suas preocupações éticas na Terra de forma holística e da qual o Homem faz parte, não caindo em ideias misantropas ou especistas, de modo a equalizar escolhas morais e que sempre que postas em causa podem não vir a favorecer a humanidade. (CURRY, 2005)

Respetivamente, é legítima a ideia de que se consiga associar estas três categorizações éticas à forma como analisamos as considerações ecológicas na arte, propondo, então, que se possa passar a vê-las como uma escala e não como uma designação que se aplica de forma binomial à arte e ao artista e estando somente isoladas formas de arte puramente antropocêntricas.

De forma exemplar, as definições da Ecoart Network e de Linda Weintraub poderão se inserir mais no deep green, dado que ambas estão dispostas a reformular o método, discurso, processo, expressão e durabilidade das suas práticas artísticas em prol da proteção da Natureza, demonstrando, assim, uma motivação ecocêntrica. Todavia, contrariamente à espectativa, Suzi Gablik, ainda que descreva o movimento como não sendo antropocêntrico e como o que promove um pensamento simbiótico com a Natureza, (quando, aditivamente, restringe-o como aquele que não tenta destruir o sistema social moderno), consequentemente, posiciona a sua definição na área mid-green, uma vez que, apesar de considerar a crise climática como um problema universal, ao colocar as necessidades da humanidade à frente de medidas ecológicas, caso estas contradigam os seus 
interesses, demonstra que se considera mais importante que outras formas de vida, não sendo, portanto, totalmente ecocêntrico.

Por fim, como estabelecido previamente, não podemos associar, na sua totalidade, a Land art ou outros movimentos artísticos alusivos das preocupações ecológicas à Ecological art. Entretanto, estas podem ser, agora, conectadas a uma shalow ethic, pois, apesar das suas explorações criativas serem sempre mais inquiridas, do que o papel do Homem/artista na Terra, o facto da sua criação utilizar apenas o natural como temática útil, ainda que para atingir novas interrogações acerca do mundo da arte, estas acabam por demonstrar iniciativa e até algum impacto na transformação da valorização humana da Natureza.

\section{CONCLUSÃO}

Em suma, no decorrer do artigo, a determinação do termo ecológico na arte foi debatida sobre diferentes pontos de vista, tanto pela sua pertinência como pela sua evolução desde os finais dos anos 60 até a atualidade. A inserção da palavra ecologia nas diferentes formas de expressão revela que apesar de se falar sobre o tópico, este não implica a nominação de determinada obra de arte como parte da Ecological art. Devido a todos os aspetos inerentes ao pensamento ecologista e propício ao contexto social e político, que tiveram grande impacto no mundo da arte, o aparecimento de movimentos, como a Land art, provocou alguma incerteza. Não obstante, seja através do impacto da obra no espectador/espaço, da idealização de transformações e transições mais sustentáveis da configuração da sociedade contemporânea ou de exemplos implícitos no processo e na produção artística, a arte ecológica refuta quaisquer argumentos criativos antropocêntricos. Posto isso, a Land art é limitada quando comparada sobre o consenso de várias definições do movimento ecológico, das quais, as suas próprias caracterizações veem a ser distinguidas a partir da ética ecocêntrica e ecológica, sendo assim, categorizadas sobre uma escala de aproximação da visão eco centralizada e simbiótica do Homem com a Natureza. De forma crescente as éticas shallow, intermediate e deep salientam a visão da Ecoart Network e de Linda Weintraub quanto à sua eficácia e pragmatismo ao estabelecer as normas ecológicas artísticas e propõem olhar para outros 
movimentos, não pertencentes como simplesmente superficiais nos seus entendimentos sobre a natureza ecológica. Sob uma reformulação terminológica da Ecological art mais pragmática e abrangente é, então, possível distinguir-se de forma coesa e franca os diferentes movimentos entre si, compreendendo-os sob uma hierarquia lógica, que sustenta o movimento tanto no passado, como no presente e futuro do mundo arte.

\section{FIGURAS}

Fig. 1 Smithson, R. (1970). Spiral Jetty [Lama, cristais de sal precipitados, rochas, água 457,2 m de comprimento e 4,6 m de largura]. Fotografia publicada a 17 April, 2005, transferida da en.wikipedia para Commons Image:CC-BY-SA-2.0, em https://commons.wikimedia.org/wiki/File:Spiral-jetty-from-rozel-point.png.

Com licença: "This work is in the public domain in the United States because it was published in the United States between 1926 and 1977, inclusive, without a copyright notice. For further explanation, see Commons:Hirtle chart as well as a detailed definition of "publication" for public art. Note that it may still be copyrighted in jurisdictions that do not apply the rule of the shorter term for US works (depending on the date of the author's death), such as Canada (50 p.m.a.), Mainland China (50 p.m.a., not Hong Kong or Macao), Germany (70 p.m.a.), Mexico (100 p.m.a.), Switzerland (70 p.m.a.), and other countries with individual treaties."

Fig. 2 Heizer, M. (1969-1970). Double Negative [Duas goivas na rocha de Morton Mesa]. Fotografia tirada a 9 de fevereito, 2007, por Clf23 na English Wikipedia, CC BY-SA 3.0 em https://commons.wikimedia.org/wiki/File:Double_Negative_Artwork.jpg Com permissão: "Permission is granted to copy, distribute and/or modify this document under the terms of the GNU Free Documentation License, Version 1.2 or any later version published by the Free Software Foundation; with no Invariant Sections, no Front-Cover Texts, and no Back-Cover Texts. A copy of the license is included in the section entitled GNU Free Documentation License." 
Fig. 3 Christo \& Jeanne-Claude. (1972-1976). Running Fence [feito de 200.000 metros quadrados de tecido pesado de náilon branco, pendurado em um cabo de aço amarrado entre 2.050 postes de aço (cada 6,4 metros, 8,9 centímetros de diâmetro) embutidos em 91 centímetros no solo, sem uso de cimento e apoiado lateralmente com cabos de sustentação (145 quilômetros de cabo de aço) e 14.000 âncoras de aterramento. As bordas superior e inferior dos 2.050 painéis de tecido foram presas aos cabos superior e inferior por 350.000 ganchos]. Fotografia publicada em 2014, por USFWS, na pixnio: Public domain images, royalty free stock photos em https://pixnio.com/vintage-photography/history-photography-pictures/aerial-photoof-long-fence-line-running-across-wide-flat-plain\#img_info

Com licença: "Image is in public domain, not copyrighted, no rights reserved, free for any use. You can use picture for any personal and commercial use without the prior written permission and without fee or obligation."

Fig. 4 Ana Ribeiro (2021). Ecological art sob uma escala ecocêntrica [Esquema desenvolvido pela autora, exemplificativo da movimentos, autores e artistas numa escala hierárquica ecocêntrica]

Com licença: Imagem da autora do artigo.

\section{BIBLIOGRAFIA}

Bann, S., \& Allen, W. Interpreting Contemporary Art. IconEditions, Nova York, 1991.

Beardsley, J. Earthworks and Beyond: Contemporary Art in the Landscape (Abbeville Modern Art Movements) Subsequent ed. Nova York: Abbeville Pr, 1998.

Bennett, D., \& Sylvan, R. The Greening of Ethics. Tucson: University of Arizona Press, 1994.

Berleant, A. The Aesthetics of Environment. Philadelphia, Pennsylvania: Temple University Press, 1995.

Celant, G. Art Povera. 1ํ ed. Westport, Connecticut: Prauger Publishers, 1969.

Collin, P. Dictionary of Environment and Ecology: Over 7,000 terms clearly defined (Bloomsbury Reference) 5o ed. Londres: A\&C Black, 2004. 
Curry, P. Ecological Ethics: An Introduction. 10 ed. Cambridge, Oxford e Boston: Polity, 2005.

Hull, L., Krug, D., Oakes, B., Rahmani, A., \& Steinman, S. Ecoart network. Fundado em 1998, acedido a 30 de dezembro, 2020, em https://ecoartweb.wixsite.com/ecoartnetwork

Kagan, S. The practice of ecological art. Publicado a 15 de fevereiro, 2014 em Https://Www.Academia.Edu/. Acedido em https://www.academia.edu/27524546/The_practice_of_ecological_art

Kastner, J., \& Wallis, B. Land \& Environmental Art (Themes and Movements) 1o ed. Londres e Nova York: Phaidon Press, 1998.

Lippard, L. R. Overlay: Contemporary Art and the Art of Prehistory. Revised ed. Nova York: The New Press, 1995.

Smith, S., \& Margolin, V. Beyond Green: Toward a Sustainable Art. 10 ed. Chicago: Smart Museum Of Art, The University Of Chicago, 2006.

Weintraub, L. To Life!: Eco Art in Pursuit of a Sustainable Planet. 1ㅇe ed. California: University of California Press, 2012. 